\title{
ARTIGOS
}

\section{MUITO ALÉM DA PANDEMIA: A HISTÓRICA CRISE NO MERCADO DE TRABALHO FORMAL E OS IMPACTOS DA COVID-19 NOS EMPREGOS DO RIO GRANDE DO SUL}

\author{
Tiaraju Salini Duarte \\ Universidade de São Paulo \\ Mateus Marzullo \\ Universidade de São Paulo
}

Eduardo Schumann ${ }^{3}$

Universidade de São Paulo

Resumo: A crise desencadeada pela difusão do Vírus SARS-CoV-2 impactou de maneira significativa não somente as relações sociais, mas também as decisões políticas no Brasil em múltiplas escalas. Nesse contexto, desde o mês de março do ano de 2020 foram sugeridas medidas para conter o avanço da COVID-19 no estado do Rio Grande do Sul, as quais resultaram em ramificações e debates acerca dos desdobramentos da doença nos indicadores econômicos, principalmente no saldo de empregos. A partir desse contexto elencamos o objetivo geral do trabalho, o qual busca analisar a estrutura do emprego formal no estado do Rio Grande do Sul em dois contextos: o primeiro, denominado de pré-pandêmico (2010 a 2019) e, o segundo, de pandêmico (janeiro a dezembro de 2020). No que tange à metodologia, foram utilizadas duas bases de dados: o Cadastro Geral de Empregados e Desempregados (CAGED) tanto na escala nacional como estadual e a Pesquisa Nacional por Amostra de Domicílios (PNAD), as quais possibilitaram observar o comportamento da taxa de desocupação no recorte temporal de 2010 a 2020. Como resultados, podemos compreender que os impactos econômicos da pandemia representam um agravamento de uma crise já existente no Brasil e no Rio Grande do Sul, fruto de uma série de transformações no mundo do trabalho brasileiro dos últimos 10 anos.

Palavras-chave: Rio Grande do Sul. Empregos. COVID-19. Precarização. Trabalho.

\section{FAR BEYOND THE PANDEMIC: THE HISTORIC CRISIS IN THE FORMAL JOB MARKET AND THE IMPACTS OF COVID-19 ON EMPLOYMENTS IN RIO GRANDE DO SUL}

Abstract: The crisis unleashed by the spread of the SARS-CoV-2 Virus has significantly impacted not only in social relations, but also the political decisions in Brazil on multiple scales. In this context, since march of 2020 measures have been suggested to contain the advance of COVID-19 in the state of Rio Grande do Sul, which resulted in ramifications and debates about the unfolding of the disease in the economic indicators, mainly in the balance of employments. From that context we listed the main goal of the work, which seeks to analyze the structure of formal employment in the state of Rio Grande do Sul in two contexts: the first, called pre-pandemic (2010 to 2019), and the second, of

1. Doutor em Geografia. Professor Adjunto da Universidade Federal de Pelotas e do Programa de Pós-Graduação em Geografia da Universidade Federal de Pelotas. Orcid: https://orcid.org/0000-0001-6817-0952. E-mail: tiaraju.ufpel@gmail.com

2. Mestre em Geografia. Professor da rede pública e privada do Rio Grande do Sul. Orcid: https://orcid.org/0000-0001-63707343. E-mail: mateusmarzullo@yahoo.com.br

3. Graduando em Geografia. Bolsista de Iniciação Científica. Orcid: https://orcid.org/0000-0001-6111-4675. E-mail: eduardoschumann01@gmail.com 
pandemic (january to december of 2020). Regarding the methodology, two databases were used: the General Register of Employed and Unemployed (CAGED) at both national and state scales and the National Household Sample Survey (PNAD), which made it possible to observe the behavior of the unemployment rate in the time frame of 2010 to 2020 . As results, we can understand that the economic impacts of the pandemic represent an aggravation of a crisis that already exists in Brazil and Rio Grande do Sul, the result of a series of transformations in the world of the brazilian work in the last 10 years.

Keywords: Rio Grande do Sul. Employment. COVID-19. Precariousness. Work.

AU-DELÀ DE LA PANDÉMIE: LA CRISE HISTORIQUE DU MARCHÉ DU TRAVAIL FORMEL ET LES IMPACTS DU COVID-19 SUR LES EMPLOIS DANS LE RIO GRANDE DO SUL

Résumé: La crise déclenchée par la propagation du virus SRAS-CoV-2 a eu un impact significatif non seulement sur les relations sociales, mais aussi sur les décisions politiques au Brésil à plusieurs échelles. Dans ce contexte, depuis mars 2020, des mesures ont été suggérées pour contenir les progrès du COVID-19 dans l'état du Rio Grande do Sul, ce qui a entraîné des ramifications et des débats sur les conséquences de la maladie sur les indicateurs économiques, principalement dans la balance d'emplois. À partir de ce contexte, nous listons l'objectif général du travail, qui cherche à analyser la structure de l'emploi formel dans l'état du Rio Grande do Sul dans deux contextes: le premier, dit prépandémique (2010 à 2019) et le second, la pandémie (janvier à décembre 2020). Concernant la méthodologie, deux bases de données ont été utilisées: le Registre Général des Salariés et des Chômeurs (CAGED) à l'échelle nationale et étatique et l'Enquête Nationale par Sondage auprès des Ménages (PNAD), qui a permis d'observer le comportement du taux d'emploi dans la période de 2010 à 2020 . En conséquence, nous pouvons comprendre que les impacts économiques de la pandémie représentent une aggravation d'une crise qui existe déjà au Brésil et dans le Rio Grande do Sul, résultat d'une série de transformations dans le monde du travail brésilien aux dernières dix années.

Mots clés: Rio Grande do Sul. Emplois. COVID19. Précarité. Travail.

Introdução

De acordo com o Centro Europeu de Prevenção e Controle de Doenças (CEPCD, 2020), a COVID19, doença com origem no vírus SARS-CoV-24 ${ }^{4}$, surgiu a partir da metrópole de Wuhan, capital da província de Hubei na China. A acelerada difusão desse vírus no mundo em conjunto com a necessidade da implementação de medidas restritivas nos mais diversos territórios, com o objetivo de barrar o alastramento da doença, geraram choques econômicos em ritmos e intensidade acima dos observados na história recente do sistema capitalista, superando a crise econômica do ano de 2008 e a grande depressão dos anos de 1930 (ROUBANI, 2020).

Logo, a variação negativa no âmbito das movimentações financeiras em escala mundial, bem como a volatilidade do mercado internacional e o decréscimo na produção industrial provocaram uma das maiores crises da história, ocasionando no pior cenário para surto da COVID-19: a queda da economia global pela metade no ano de 2020 (OCDE, 2020). Ferreira Junior e Santa Rita (2020) observam que a difusão do SARS-CoV-2 potencializou a fragilidade do sistema econômico em todo o planeta, por exemplo, com a queda no preço do barril de petróleo, o enfraquecimento de moedas, aumento da dívida pública e o desemprego.

Todavia, destaca-se que a temporalidade de difusão do SARS-CoV-2 pelo mundo não se manifestou de forma homogênea pelo espaço. A velocidade de contaminação está relacionada diretamente ao processo de integração no sistema capitalista das aglomerações urbanas, tendo em vista que a conectividade em redes de densidade diversas ditou o ritmo de dispersão da doença (SPÓSITO; GUIMARÃES, 2020), produzindo um processo desigual de difusão e, por consequência, o escalonamento dos impactos.

Estas variadas formas de espacialização são relacionadas a inúmeros fatores, desde a ordem de integração econômica dos territórios, passando por particularidades regionais e culturais,

\footnotetext{
${ }^{4}$ Severe Acute Respiratory Syndrome Coronavirus Disease, 2019.
} 
discursos políticos de resistência às medidas sanitárias, falta de fiscalização etc. Os contextos diversos de enfrentamento da doença culminaram em alguns casos com a ausência de políticas públicas efetivas para mitigar os efeitos da pandemia.

Na conjuntura brasileira, o primeiro caso registrado da COVID-19 data do dia 26 de fevereiro de 2020, no estado de São Paulo, evidenciando o significativo grau de conectividade deste nas grandes cadeias econômicas internacionais. SANTOS (1996), ao discutir a integração do território nacional, analisa a formação de áreas densas e rarefeitas no processo de produção do espaço, destacando o papel central que o estado de São Paulo (e sua capital) exercem no sistema financeiro mundial. Essa importância está relacionada diretamente com as bases técnicas que compõem uma geografia dos fluxos no território, as quais possibilitaram que se exerça um papel de comando no Brasil (SANTOS; SILVEIRA, 2001).

Em consonância com a centralização da estrutura técnica, há no estado de São Paulo uma diversificação de rotas aéreas que utilizam os aeroportos de São Paulo/Guarulhos (Governador André Franco Montoro), São Paulo/Congonhas (Deputado Freitas Nobre) e São Paulo/Campinas (Viracopos) como principal base de entrada de passageiros internacionais. Como destaca Aguiar (2020, p. 58), o aeroporto internacional de Guarulhos representa o "maior entroncamento aeroviário do Brasil e o mais movimentado da América do Sul".

Após os primeiros casos registrados neste recorte espacial, diversos governos tanto na escala local (municípios), bem como nas unidades da federação (estados) estruturaram variadas estratégias de planejamento e organização para o enfrentamento do vírus; fronteiras foram fechadas, aumentouse a capacidade de atendimento na saúde e foram criadas propostas de restrições no funcionamento de alguns setores da economia. Essas medidas (entre outras que poderiam ser citadas) serviriam como barreiras (permeáveis) para a difusão da doença (ZANATTA, 2020).

Especificamente no caso do Rio Grande do Sul, adotou-se a organização regional da saúde por meio do denominado "Modelo de Distanciamento Controlado5", o qual teve como propósito conciliar a desigualdade na disseminação do vírus nas regiões de saúde, equilibrar a estrutura hospitalar regional e mitigar os potenciais processos de recessão econômica. Sendo assim, de maneira geral, houve um esforço em controlar a disseminação do vírus, contudo, em conformidade com grande parte do mundo, o Sul do Brasil não escapou do desempenho negativo nos setores produtivos.

Frente a esse contexto que resultou em acirrados debates sobre os desdobramentos dos efeitos da pandemia nos indicadores econômicos, principalmente no saldo de empregos, é que elencamos o objetivo geral do trabalho, o qual busca analisar a estrutura do emprego formal no estado do Rio Grande do Sul em dois contextos: o primeiro, denominado de pré-pandêmico (2010 a 2019) e, o segundo, de pandêmico (janeiro a dezembro de 2020).

A escolha em estabelecer um estudo sobre Rio Grande do Sul justifica-se tendo em vista que os impactos da difusão do SARS-CoV-2 resultaram em significativo decréscimo econômico no estado no ano de 2020, culminando com um dos maiores saldos negativos de empregos formais do Brasil neste período, segundo dados do Cadastro Geral de Empregados e Desempregados (CAGED, 2020). Ademais, durante o século XXI no estado, são observados momentos de fortes declínios econômicos acompanhados de breves retomadas, o que pode evidenciar que a conjuntura desenvolvida pela

\footnotetext{
5 o Modelo de Distanciamento Controlado do Rio Grande do Sul foi construído com base em critérios de saúde e de atividade econômica. Criou-se um sistema de bandeiras, com protocolos obrigatórios e critérios específicos a serem seguidos pelos diferentes setores econômicos. Conforme o grau de risco, cada região recebe uma bandeira nas cores amarela, laranja, vermelha ou preta (RIO GRANDE DO SUL, 2020).
} 
COVID-19 representa o agravamento de uma crise já existente no território gaúcho, não sendo essa doença o único motivo da queda de empregos formais.

Para compreender tal perspectiva, o presente artigo estabeleceu uma periodicidade dos fatos relativos ao mercado de trabalho formal e seus desdobramentos no século XXI, sendo eles: aplicação de uma agenda neoliberal na economia; crise política de 2014-2016 (que culmina com o processo de impeachment da então presidente Dilma Roussef), reforma trabalhista no ano de 2017 e a ascensão da pandemia da COVID-19 em 2020.

Em termos metodológicos, utiliza-se dados históricos CAGED tanto na escala nacional como estadual, a fim de compreender o saldo de empregos formais. Salienta-se que a opção em utilizar as informações desse sistema refere-se ao elevado grau de confiabilidade, uma vez que todo empregador deve realizar o registro da movimentação de demissões e admissões nas plataformas do CAGED mensalmente. Além desses, foram utilizados dados da Pesquisa Nacional por Amostra de Domicílios (PNAD), os quais possibilitaram observar o comportamento da taxa de desocupação no recorte temporal da pesquisa.

Por fim, na escala estadual realizou-se a organização, tabulação e análise dos dados do CAGED, tendo como base os Conselhos Regionais de Desenvolvimento do Rio Grande do Sul (COREDES) durante o ano de 2020. Assim, foram agrupadas as atividades econômicas e realizados mapeamentos por regiões através do software livre QGIS.

\section{Muito além da COVID-19: o contexto temporal pré-pandêmico e a precarização do trabalho no Brasil}

O desemprego ocasionado pela pandemia do coronavírus transformou-se no ano de 2020 em palanque político para justificar a crise econômica do Estado brasileiro, servindo de "muleta" para os problemas estruturais ocasionados por uma série de transformações no mundo do trabalho.

Não pretendemos, neste primeiro momento do artigo, negar o impacto econômico originado a partir dessa conjuntura, todavia, torna-se necessário compreender o cenário histórico, tanto brasileiro como gaúcho, do mundo do trabalho anterior a 2020, a fim de demonstrar que a COVID-19 representa o agravamento de um contexto sistêmico produzido pela agenda econômica brasileira.

Importante salientar que ao longo da história econômica brasileira do século XX diversos ciclos de crise e retomada foram se estabelecendo, os quais são analisadas por autores como Furtado (1966; 1974; 2003), Prado Jr. (2008); Cruz (1983); Castro e Souza (1985); Giambiagi e Villela et al. (2011), entre outros.

Desse modo, o desenvolvimento brasileiro esteve atrelado a construção de agendas que orquestraram a produção de uma lógica de dependência do mercado internacional, a qual se intensificará com a ascensão do modelo político e econômico neoliberal. Destacamos que esse relaciona-se a um projeto originado na década de 1970 assentado na tentativa de consolidar ideias como o livre mercado, livre comércio, responsabilidade pessoal, autonomia etc., que maquiam a tentativa de sustentação da classe capitalista com centro de poder (HARVEY, 2011).

No movimento de ascensão do modelo neoliberal cria-se, principalmente nos anos de 1990, condições necessárias para inserir de forma subordinada o Brasil na economia mundial. O receituário para este processo tem como um de seus marcos o denominado "Consenso de Washington", o qual formalizou diretrizes que objetivavam reduzir o papel do Estado por meio de privatizações, disciplina fiscal, reforma tributária, liberalização financeira e comercial (GENNARI, 2001).

Nesse período, a agenda de reformas construída no território nacional centra-se principalmente no processo de privatização, o que ocasiona aumento significativo de investimentos externos diretos no Brasil. Esses serão a base do processo de reestruturação centrada na abertura para o capital 
internacional, promovendo a desnacionalização da economia em importantes segmentos (BENETTI, 2000).

A política econômica de dependência construída pelo Estado brasileiro ao longo de sua história, em conjunto com o acirramento da inserção de todo o território nacional nos moldes neoliberais, terá "novos" contornos no século XXI, sendo que um dos principais focos centra-se nas transformações no mundo do trabalho por meio de ideias voltadas à "flexibilização" dos direitos trabalhistas (ALVES, 2009). Derivado dessas mudanças, o desemprego e a precarização do trabalho tornaram-se um problema crônico que está inserido em um contexto econômico que busca potencializar lucros de empresas, possibilitando a acumulação de capital.

Antunes e Filgueiras (2020, p. 35-36) reforçam que o discurso do modelo de acumulação flexível tem ocasionado um nefasto impacto no mundo do trabalho mediante a ideia do "reino da liberdade", o que produz uma "sociedade dos excluídos e dos precarizados". A desregulamentação das leis trabalhistas no Brasil caminha nesse sentido ao produzir um discurso anti-sindical e autonomista do trabalhador, sendo que este teria a "liberdade" individual de decidir junto ao empregador sua situação de labor. Essas proposições, encontram-se temporalmente em um momento de ruptura política no cenário brasileiro, com a ascensão de ideias voltados ao mercado, principalmente, no período pósimpeachment da então presidente Dilma Rousseff no ano de 2016.

A reforma trabalhista ${ }^{6}$ representa um marco desse processo, através da proposta aprovada no ano de 2017 pelo então presidente da república Michel Temer. Os autores Druck, Dutra e Silva (2019, p. 293) analisam que o movimento que buscou coordenar o processo de transformações na legislação trabalhista possui três bases: o primeiro, seria a "expressão da ação classista do capital contra uma classe trabalhadora"; o segundo, "o quadro de excepcionalidade, em que as instituições da democracia representativa se encontram em crise" e, o terceiro, que "contesta o paradigma protetivo dos trabalhadores".

Estes pilares discursivos encontram respaldo nos ideais neoliberais, pavimentando uma agenda de reformas pró-mercado que culminou com a mudança na legislação trabalhista brasileira. Esse enunciado pode ser visualizado, por exemplo, na fala do então ministro da economia Henrique Meirelles a respeito da reforma, a qual teria como intuito "gerar mais empregos e melhorar a vida dos brasileiros" (FOLHA DE SÃO PAULO, 2017).

Contudo, após três anos da aprovação da lei 13/467 de 2017 nota-se o movimento contrário: a vida do proletariado foi dificultada e os índices de emprego não mudaram significativamente no território nacional. A reforma aumentou o número de contratos temporários, o que culmina com a insegurança do trabalhador e sua "submissão" a condições de trabalho precárias. Outros desdobramentos perversos referem-se ao aumento da jornada de trabalho, redução de garantias como férias, isonomia salarial, dificuldade de acesso à justiça do trabalho etc.

Portanto, a reforma federal não ofereceu bases jurídicas para superar a crise, não gerou saldo de emprego significativo e piorou a qualidade de vida dos trabalhadores brasileiros. O que se efetuou foi uma tímida oferta de subempregos, ocasionando o aumento quantitativo de pessoas que buscam o sustento por conta própria (COSTA, 2020).

Santos (2003) salienta que não é o Estado que se ausenta de responsabilidade, mas, sim, que o foco dessa estrutura estará voltado aos detentores do poder econômico. A maioria da população, elo mais frágil do sistema, vive, então, a perversidade do mercado de trabalho; o desemprego e o

\footnotetext{
6 A reforma trabalhista (Lei 13.467, de 2017) mudou as regras relativas a remuneração, plano de carreira e jornada de trabalho, entre outras. A norma foi aprovada para flexibilizar o mercado de trabalho e simplificar as relações entre trabalhadores e empregadores (BRASIL, 2020).
} 
subemprego tornam-se "naturais", a precarização começa a transformar-se na regra e a esperança do pleno emprego (que gera segurança legal para os trabalhadores) transforma-se em saudade de um futuro prometido.

Neste contexto controverso de reformas pró-mercado, a pandemia ocasionada pela COVID-19 produziu discursos político/partidários para justificar o desemprego, como a falência de empresas, a queda no consumo, entre outros. Contudo, a ideia de que o vírus foi o principal fator do atual desemprego no Brasil deve ser compreendida com um olhar apurado, tendo em vista que, ao analisarmos indicadores como a taxa de desocupação ${ }^{7}$ no território nacional dos anos de 2014 a 2020 - disponibilizada pelo PNAD Contínua (GRÁFICO 01) -, podemos constatar que a situação do mercado de trabalho brasileiro não demonstra consideráveis sinais de recuperação.

Gráfico 1 - Taxa de desocupação no Brasil (porcentagem trimestrais móveis entre dezembro de 2014 e dezembro de 2020).

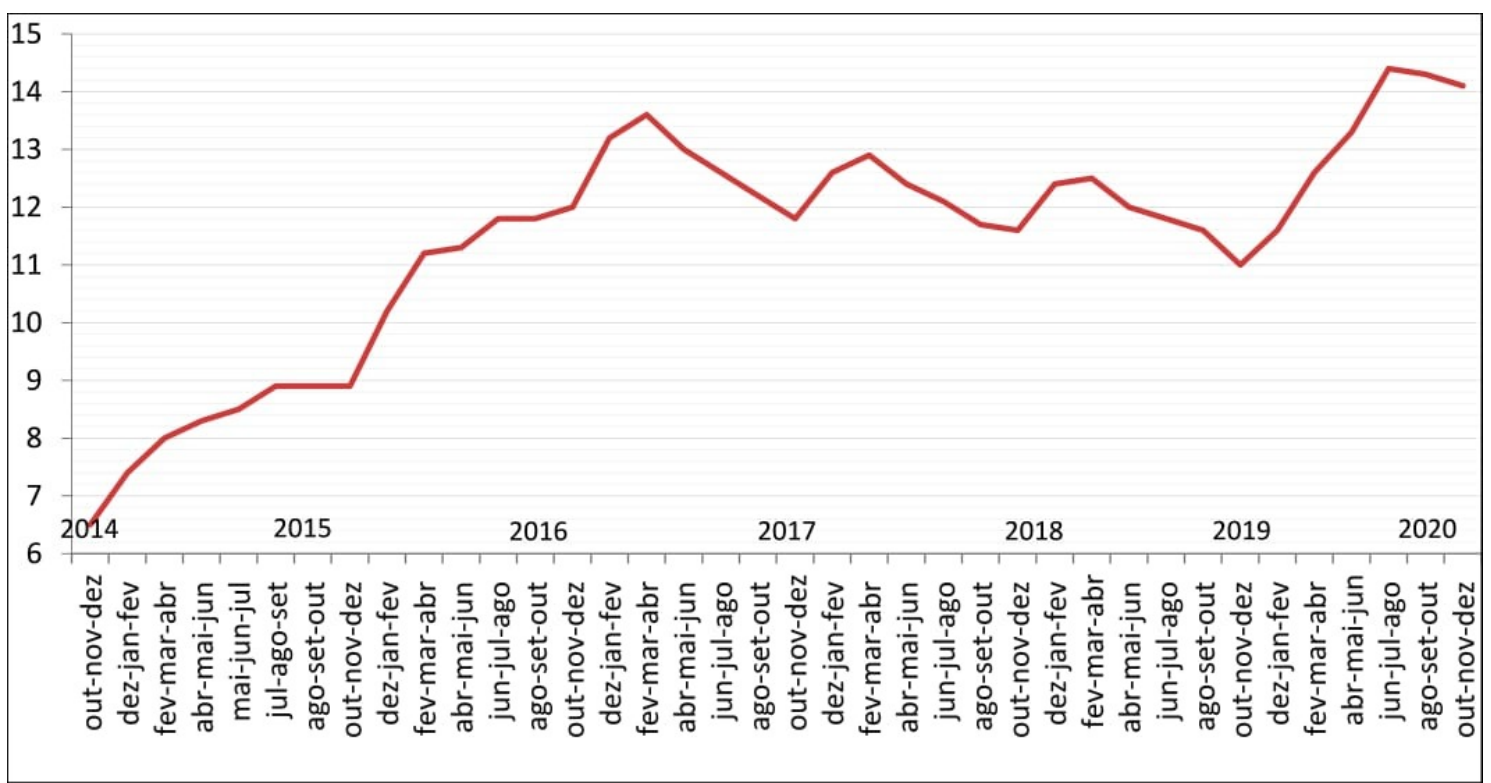

Fonte: IBGE/PNAD, 2020. Elaborado pelos autores.

A conjuntura histórica das reformas no mundo do trabalho apresenta uma possível estabilidade da população desocupada, todavia, com auxílio dos dados da Figura 01, observamos que as mudanças legais tiveram um impacto baixo no processo de redução do desemprego. A ascensão da desocupação que teve como início, em nosso recorte temporal, no ano de 2014 atingiu seu auge no primeiro trimestre de 2017; após, observa-se linearmente um processo tímido de retração deste indicador e novamente o aumento da desocupação na passagem de 2019 para 2020.

Importante destacar que a vigência da reforma trabalhista se deu no mês de novembro do ano de 2017 e, desde então, não apresentou melhoras relevantes na taxa de desocupação. Na outra face, podemos constatar que existiu no mesmo período um processo de precarização do serviço impulsionado não somente pela crescente informalidade, mas, também, devido aos novos contratos de trabalho possíveis derivados da mudança legal.

Segundo dados da PNAD contínua (2020), 41,1\% da população economicamente ativa encontra-se na informalidade, sendo que essa tendência é acompanhada pela redução dos postos de trabalho formais no Brasil. No ano de 2014, existiam um total de 36 milhões de pessoas com

\footnotetext{
${ }^{7}$ A taxa de desocupação é a percentagem da população economicamente ativa que não está inserida no emprego formal ou em atividades informais (IBGE, 2020).
} 
carteira assinada; no ano de 2018, esse número havia reduzido para 32 milhões. Com relação aos postos de trabalho fora da Consolidação das Leis Trabalhistas (CLT), podemos constatar um aumento de 10 milhões no ano de 2014 para um total de 11 milhões no ano de 2018.

Os dados também demonstram um acréscimo de trabalhadores por conta própria; de 2012 a 2019 a proporção subiu de 22,8\% para $25,8 \%$ e os trabalhadores com carteira assinada caíram de 38,4\% para 35,8\%. Logo, mesmo que o indicador de desocupação nos anos de 2017 a 2019 tenha reduzido, a situação ocupacional dos trabalhadores se precarizou.

No ano de 2020, os dados confirmam que nos primeiros meses do ano (janeiro e fevereiro meses que não tiveram reflexos da pandemia) a taxa de desocupação entre os cidadãos brasileiros mostrou-se com poucas modificações quando comparado aos dados dos anos anteriores, pavimentando um possível caminho para o aumento do número de pessoas desocupadas com ou sem a COVID-19.

\begin{abstract}
A taxa de desocupação, que flutuava ao redor de 7\% no início de 2014, atingiu seu ápice nos primeiros meses de 2017, quando ultrapassou a marca dos $13 \%$. Nesse período, o número de desempregados no Brasil mais que dobrou, atingindo 13 milhões de pessoas no auge da crise [...]. Isso porque, no trimestre que se encerrou em fevereiro de 2020, a taxa de desocupação no país ainda era de $11,6 \%$, ou seja, apenas 1,6 ponto percentual abaixo da registrada no mesmo trimestre de 2017. (MATTEI e HEINEN, 2020, p. 31)
\end{abstract}

Portanto, antes do contexto pandêmico, o Brasil já atravessava um período delicado em relação ao mercado formal de trabalho. Assim, defende-se que o contexto ocasionado pela difusão do SARSCoV-2, que emerge no ano de 2020 principalmente a partir de março, representa um agravamento de uma crise econômica que está atrelada a um projeto de concentração de renda no território nacional.

No que se refere ao Rio Grande do Sul, podemos observar através da série histórica dos saldos de empregos (GRÁFICO 02) que há um decréscimo no acumulado a partir do ano de 2010.

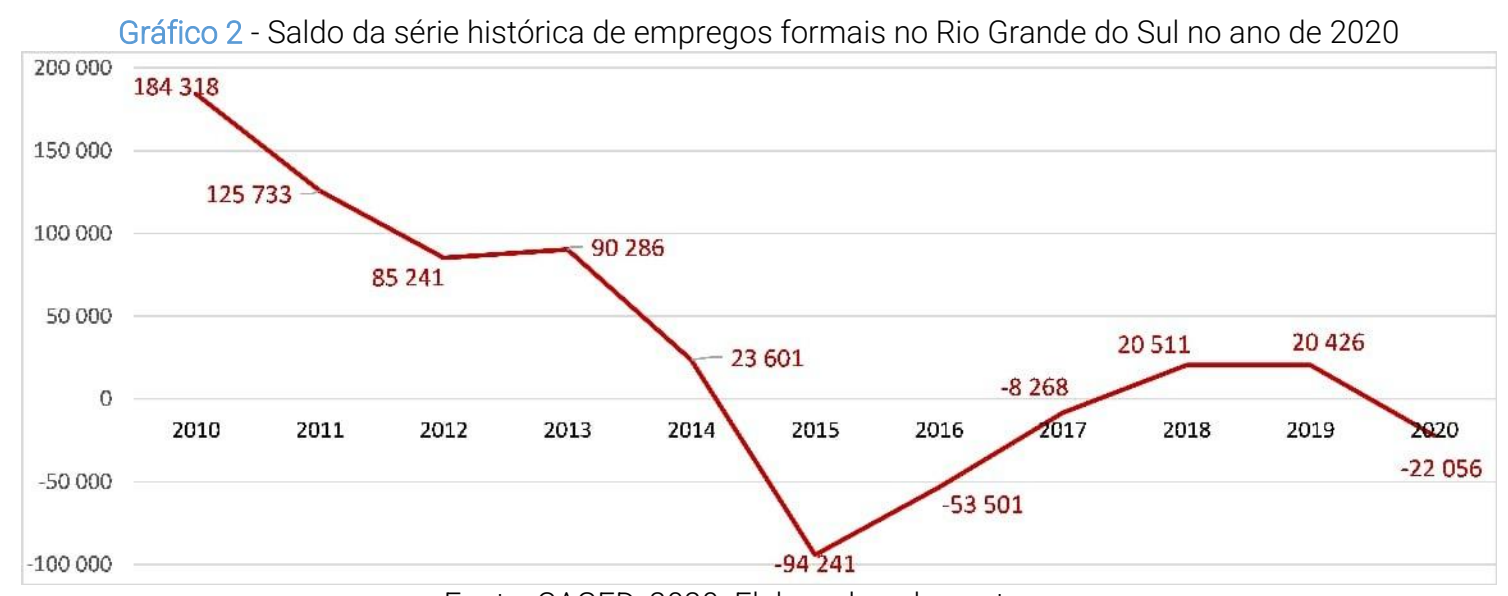

Fonte: CAGED, 2020. Elaborado pelos autores.

A tendência do estado acompanha o movimento nacional de queda na oferta de empregos formais no período de 2010 a 2015, uma retomada nos anos de 2015 a 2018 e um pequeno decréscimo no ano de 2018 a 2019 (recorte temporal em que a Lei 13/467 estava em vigor).

Ao analisarmos os dados referentes aos setores econômicos (TABELA 01) no período de 2014 a 2020, compreende-se que historicamente existe déficit no saldo de empregos por setor no Rio Grande do Sul. Todos os segmentos evidenciaram, em períodos diferentes no recorte temporal 
analisado, queda na oferta de emprego formal, sendo os setores mais impactados em números absolutos a Indústria e a Construção Civil.

Tabela 1 - Saldo de empregos formais por setor no Rio Grande do Sul no período de 2014 a 2020

\begin{tabular}{|l|r|r|r|r|r|}
\hline \multicolumn{1}{|c|}{ ANO/SETOR } & \multicolumn{1}{|c|}{ Indústria } & \multicolumn{1}{c|}{ Serviços } & \multicolumn{1}{c|}{ Agropecuária } & \multicolumn{1}{c|}{ Construção } & \multicolumn{1}{c|}{ Comércio } \\
\hline Saldo 2014 & -17.938 & 28.551 & -88 & -856 & 13.932 \\
\hline Saldo 2015 & -54.596 & -13.002 & 1.148 & -14.274 & -13.515 \\
\hline Saldo 2016 & -27.499 & -12.118 & 1.443 & -10.307 & -5.043 \\
\hline Saldo 2017 & -8.963 & -32 & -1.482 & -3.369 & 5.169 \\
\hline Saldo 2018 & 708 & 17.793 & -1.445 & 1.404 & 1.623 \\
\hline Saldo 2019 & -2.306 & 18.177 & 209 & -3.580 & 7.944 \\
\hline Saldo 2020 & 3.995 & -22.935 & 652 & 870 & -4.638 \\
\hline
\end{tabular}

Fonte: CAGED, 2020. Elaborado pelos autores.

Diante desse contexto, revela-se que a crise do emprego no Rio Grande do Sul alastra-se na última década, observando momentos de pequenas retomadas e fortes declínios. Assim, o estado vivenciou momentos em que o saldo de empregos formais foi menor do que no período pandêmico em alguns setores produtivos, como exemplo no ano de 2015 com saldo negativo no setor comercial de 13.515 vagas.

Salienta-se, ainda, que alguns setores obtiveram saldos positivos (Indústria, Agropecuária e Construção) ao longo do ano 2020, todavia, em anos anteriores vivenciaram sérios decréscimos nas vagas formais, como a Indústria (-54.596) e a Construção Civil (-14.272) no ano de 2015.

Na contramão do saldo negativo de desemprego e da crise histórica vivenciada pelo Rio Grande do Sul, constata-se que existe no período 2010 a 2017 não só o aumento do Produto Interno Bruto (PIB), mas também do PIB per capita no estado acima da média nacional (IBGE, 2017). Frente a esses indicadores, o que se nota é a existência efetiva no Rio Grande do Sul de uma conjuntura econômica que desencadeia um acréscimo da concentração de renda, ocasionando aumento da pobreza nos últimos anos. Como salientam Comim e Bagolin (2002), o Rio Grande do Sul não é um estado pobre, contudo, existem muitas pessoas pobres que vivem nele.

\section{O contexto pandêmico e os impactos da COVID-19 no mercado de trabalho formal}

A pandemia da COVID-19 provocou diversos impactos no cenário econômico e social derivados, principalmente, das medidas de controle de circulação populacional, as quais tinham como intuito conter a difusão do SARS-CoV-2. Essa forma de controle estendeu-se, também, para os setores que potencializavam o contágio viral (Comércio, Serviços, Indústria etc.), diminuindo a atividade econômica e o movimento de capital. Essa perspectiva vai ao encontro da reflexão proposta por Catão (2016, p. 04) o qual, por meio da análise da dengue no estado de São Paulo, aponta que existem possibilidades de construir barreiras conjunturais que podem mitigar os efeitos de determinada doença com base na "gestão bem conduzida no controle do vetor".

Contudo, as confusões políticas no contexto brasileiro e o descompasso da decisão dos gestores públicos em diversas escalas (municipal, estadual e federal) ocasionaram uma maior permeabilidade das barreiras sanitárias. Infelizmente, esse desencontro de estratégias acabou por transformar o Brasil em um dos principais epicentros da COVID-19 no mundo. 
Tendo em vista o contexto turbulento e confusamente percebido/construído, as medidas não só falharam na contenção da doença, como também geraram uma redução abrupta nas previsões de estabilidade econômica, provocando crises nos mais diversos setores. No território nacional houve, em nosso recorte temporal, severos decréscimos nos indicadores econômicos, impactando diretamente na oferta de empregos e agravando uma crise já existente.

Ao analisarmos os dados disponibilizados pelo Registro de empregados e desempregados (CAGED, 2020) do ano de 2020 é possível identificar as variações na promoção de empregos durante o período pandêmico. Na distribuição do saldo de empregos formais ${ }^{8}$ acumulado por unidades da Federação, nota-se nas regiões Sul, Sudeste e nordeste os índices mais elevados (FIGURA 01).

Figura 1 - Saldo de empregos formais no Brasil no ano de 2020

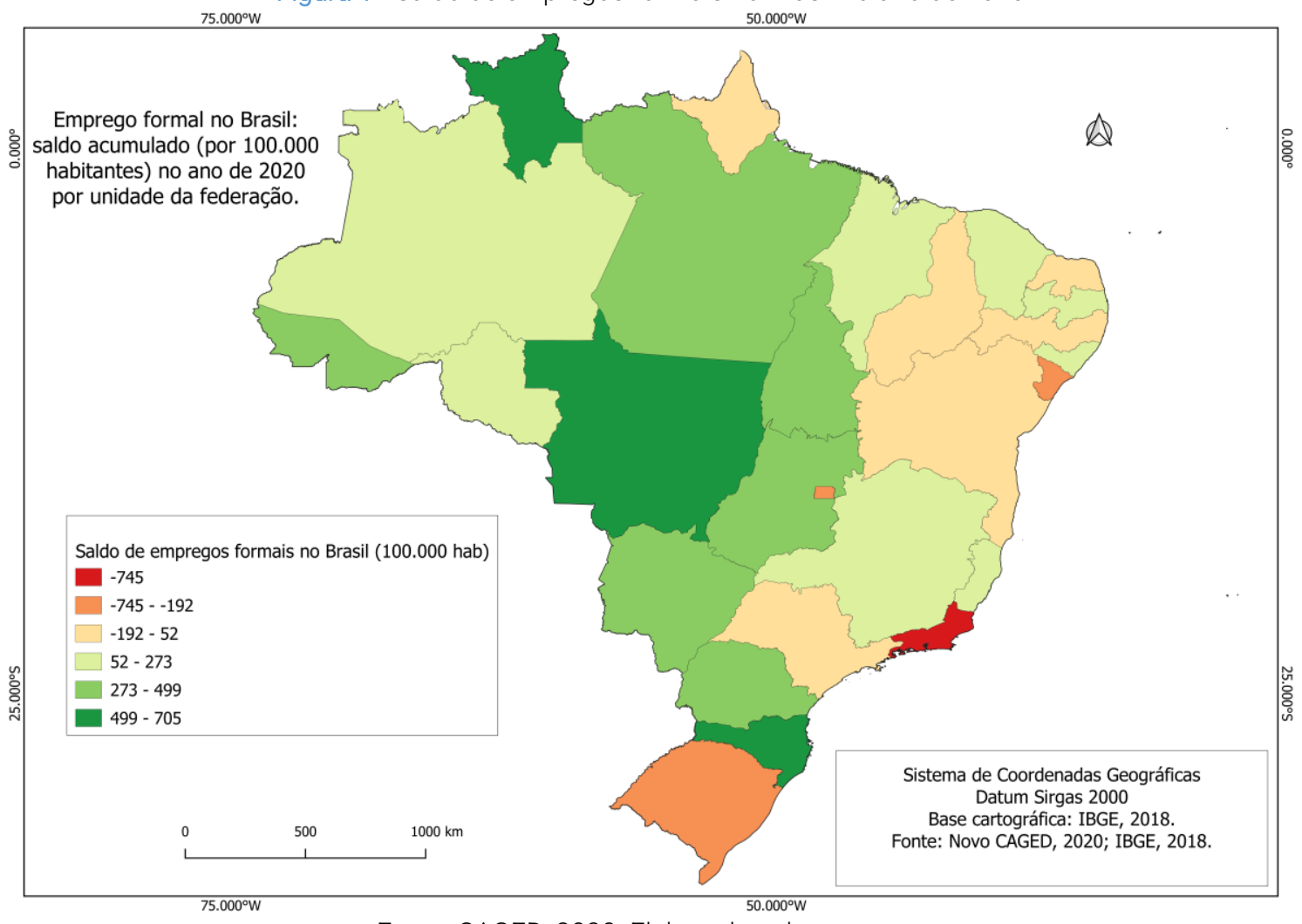

Fonte: CAGED, 2020. Elaborado pelos autores.

Apontamos, segundo os dados do CAGED (2020), que os menores saldos de empregos por 100 mil habitantes localizam-se nos estados do Rio de Janeiro, Rio Grande do Sul, São Paulo, Sergipe e Distrito Federal. Logo, o estado gaúcho no período pandêmico não escapou da regra geral vivenciada no Brasil, obtendo saldo negativo na geração de empregos.

Dentro da lógica de empregos formais no Rio Grande do Sul, há o fechamento de estabelecimentos (a partir do mês de abril do ano de 2020) e, por conseguinte, demissões em vários segmentos, pavimentando um caminho que já era traçado nos anos anteriores, conforme os dados da Figura 03 apontaram. A maior parte dos agrupamentos das atividades que empregam formalmente sofreram queda no somatório acumulado ou obtiveram um pequeno acréscimo.

O setor Agropecuário foi um dos menos afetados pela crise da COVID-19 (saldo de 652 empregos formais gerados), tendo em vista a existência de concordância internacional de que os

\footnotetext{
8 Saldo dos empregos formais equivale a diferença entre as admissões e os desligamentos dos trabalhadores no âmbito da Consolidação das Leis de Trabalho (CLT) (CAGED, 2020).
} 
governos não deveriam impor medidas para obstruir as cadeias agroalimentares globais, pois estas poderiam provocar consequências desastrosas para a população (OMC, 2020).

Outros setores com menor impacto no saldo formal de empregos foram a Indústria, com saldo positivo de 3.995 vagas formais e a Construção Civil com saldo de 870 empregos. Destaca-se que o primeiro teve acentuada interrupção nos dois primeiros semestres do ano de 2020 e, posteriormente, uma retomada que possibilitou o aumento de vagas. O segundo, devido às características das funções laborais (atividades realizadas em áreas abertas com extensões maiores) não sofreu de maneira incisiva com as restrições.

Já os setores de Serviços (-22.935 empregos) e Comércio (-4.638) foram os mais prejudicados com as medidas de distanciamento (TABELA 01). Conforme informações do Comitê de Crise do Estado do Rio Grande do Sul, esses representavam os maiores potenciais para impulsionar a difusão da doença (RIO GRANDE DO SUL, 2020). Nesse sentido, as diferenças no tratamento das atividades econômicas durante a pandemia relacionam-se diretamente com a desigual distribuição espacial do emprego e desemprego no estado (FIGURA 02).

\section{Figura 2 - Mapa da distribuição do emprego formal no Rio Grande do Sul: saldo acumulado (por 100.000 habitantes)} do ano de 2020 por conselho regional de Desenvolvimento.

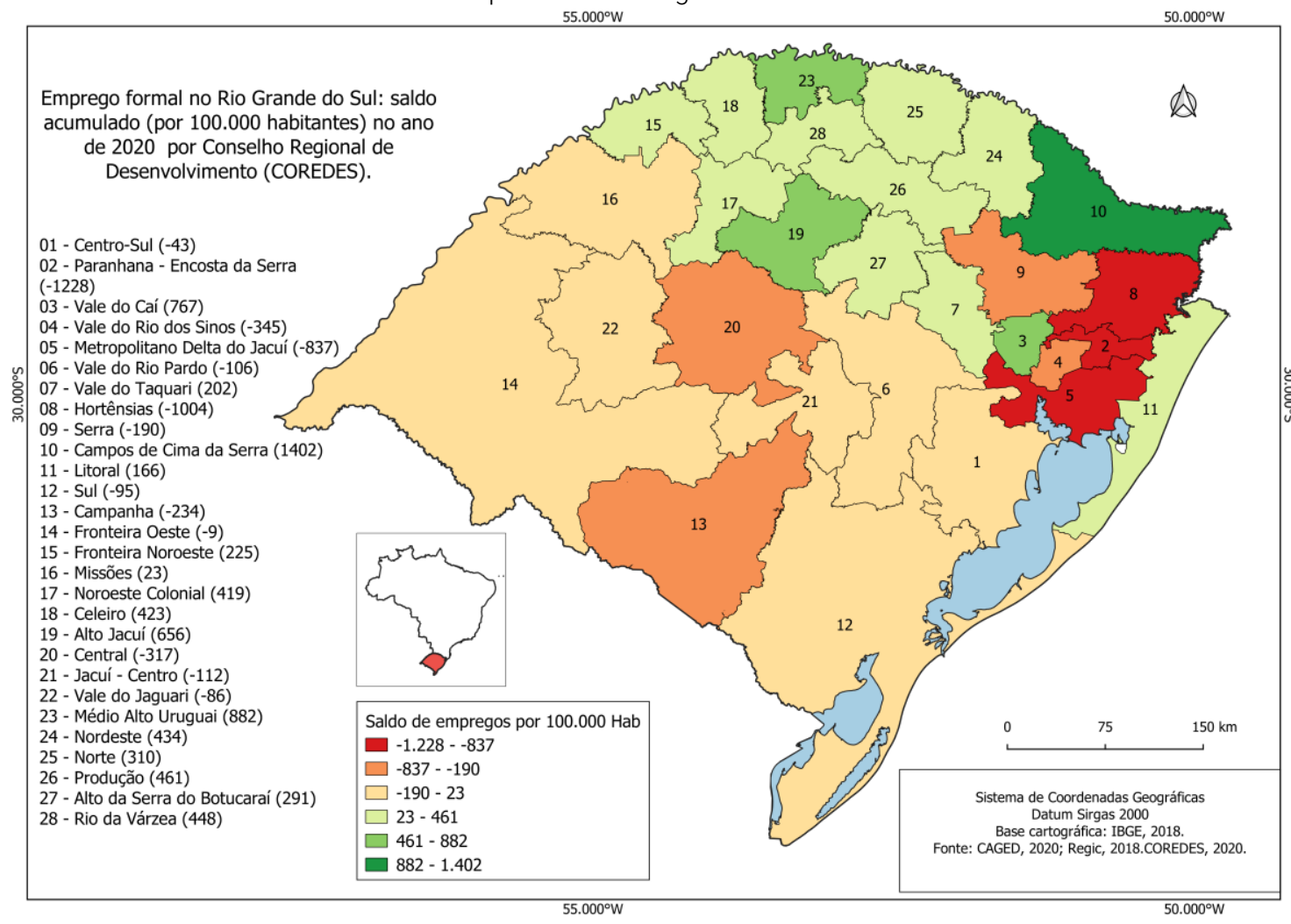

Fonte: CAGED, 2020. Elaborado pelos autores.

Nessa visualização, pode-se constatar a diferença regional dos impactos, levando em consideração o valor populacional de cada região. Com base na distribuição espacial do saldo regional de empregos no Rio Grande do Sul é possível observar, inicialmente, uma concentração negativa maior nas regiões dos COREDES que fazem parte da Região Metropolitana de Porto Alegre - RMPA- (saldo de até -1.228 empregos para cada 100.000 habitantes). Conforme salienta Soares (2012), esse recorte espacial concentra parte significativa da estrutura econômica do setor de Comércio, Serviços e Indústria (fortemente afetados pela pandemia). 
Faria et al. (2020) e Duarte et al. (2020) destacam que, segundo a lógica de ocorrência em diversas partes do mundo, a RMPA foi o primeiro grande centro de entrada da doença e posteriormente ocorreu o alastramento para a Região Metropolitana da Serra Gaúcha (RMSG), tendo como principal município Caxias do Sul.

Forma-se, por conseguinte, um arco perimetropolitano do impacto da doença no entorno da RMPA; os polos regionais mais atingidos pela crise foram Porto Alegre, Novo Hamburgo e Caxias do Sul, já o COREDE com maior saldo negativo por 100.000 mil habitantes foi o das Hortênsias. Neste último, encontram-se municípios como Gramado e Canela, os quais são grandes centros turísticos brasileiros, setor extremamente impactado pela pandemia.

Ao analisar especificamente os dados referentes à dinâmica de empregos do município de Gramado, que possui uma população estimada 36.555 (IBGE, 2020), nota-se um saldo negativo de total de 190 empregos por 100 mil habitantes A referida localidade figura entre os 10 municípios com maior número de desemprego do estado no período analisado, totalizando quase $5 \%$ de sua população desempregada de janeiro a dezembro do ano de 2020. No momento de maior impacto (agosto), o município obteve saldo negativo de 3.233 empregos, totalizando aproximadamente 10\% da população do município.

No outro lado, existem regiões nas quais o impacto da pandemia teve menor força no Rio Grande do Sul no saldo de empregos. Espacialmente, a região norte do estado obteve melhores indicadores no período pandêmico. Salienta-se que este recorte espacial possui uma base consolidada economicamente a partir da integração entre Indústria e Agricultura. Essa região passou por significativas transformações em sua base produtiva ao longo de sua história, tendo no século XXI uma estrutura de granjas e o predomínio de pequenos e médios produtores integrados a um setor agroindustrial (HEIDRICH, 2000).

De modo geral, ocorreu um maior impacto da pandemia nos COREDES que possuem sua dinâmica centralizada nos setores de Comércio e Serviços, os quais obtiveram saldos negativos na geração de empregos e mergulharam ainda mais na crise econômica já vivenciada pelo estado. Nesse sentido, mesmo que exista uma ideia de crise econômica que se manifesta de forma igualitária, espacialmente, há diferenças significativas na forma como territorializa-se os níveis de emprego e desemprego. Assim, não podemos pensar o espaço de forma unilateral, tendo em vista que existem desigualdades no processo de manifestação do capital (SANTOS, 1996).

\section{Considerações finais}

A pandemia da COVID-19 ocasionou uma série de consequências depressivas nos setores estruturais da sociedade brasileira (saúde, economia etc.), impactando diretamente a população na escala local. Dessa forma, devido à necessidade do isolamento social a fim de evitar o contágio do SARS-CoV-2, muitas atividades econômicas foram limitadas em suas capacidades produtivas, ocasionando sequentes demissões de trabalhadores no Brasil.

Contudo, podemos demonstrar, ao longo do trabalho, que o Brasil - antes mesmo da pandemia ocasionada pela COVID-19 - mergulhava em uma crise econômica que que já se alastrava desde o início da segunda década do século XXI. Essa conjuntura ocasionou mudanças de cunho político/econômico no território nacional, as quais colaboraram com uma agenda de reformas prómercado. As transformações na legislação trabalhista em conjunto com as novas formas de contratação geraram uma estabilidade nas taxas de desocupação, todavia, precarizaram de maneira acentuada a vida dos trabalhadores. 
Regionalmente, o Rio Grande do Sul no período de 2010 a 2019 seguiu esta mesma premissa, conforme demonstram os dados da série histórica de demissões que antecede o contexto pandêmico, tendo como auge da crise o ano de 2015. Mesmo com a agenda de reformas e a ascensão neoliberal, não foram observados nos dados analisados significativas melhoras nos indicadores no período de 2017 a 2019, o que indica que a Lei 13.467 não auxiliou na melhora das condições de vida da população.

No que tange ao ano de 2020, o estado gaúcho observou um saldo negativo de quase 25 mil postos de trabalho, provocando o agravamento da conjuntura econômica. Porém, mesmo que os números sejam totalizantes de um determinado fenômeno, os impactos da pandemia não se manifestam de forma homogênea no estado. Nesse sentido, mostramos que cada Conselho Regional teve características distintas no processo de absorção dos impactos no saldo de emprego derivados do alastramento da doença. Ademais, é notório na pesquisa que os COREDES com força econômica principal nos setores de Serviços e Comércio vivenciaram maiores impactos no recorte temporal pandêmico.

Apontamos, ao longo do texto a existência de um grande cinturão de desemprego que alastrase da RMPA a RMSG, decorrente das característica econômica desse recorte espacial, o qual tem como base os segmentos mais afetados pelas normatizações sanitárias de isolamento social. Também, podemos constatar que o COREDE com maior impacto negativo no saldo de empregos foi o das "Hortênsias", sendo que o principal polo econômico desse é município de Gramado, o qual possui como matriz econômica principal o turismo.

Os COREDES com menor impacto no saldo de emprego formal localizam-se principalmente na região norte do estado e obtiveram tal resultado devido à sua estrutura econômica pautada em grande medida nas pequenas propriedades altamente integradas ao setor industrial. A característica socioterritorial desse recorte possibilitou que os impactos no mundo do trabalho formal fossem menores quando comparado com as regiões metropolitanas do estado e os municípios altamente dependentes do setor de Comércio e Serviços. Logo, a especialização dos lugares deve ser levada em consideração não somente para analisarmos os impactos econômicos deixados pelo contexto da COVID-19, mas também para estruturar estratégias através de políticas públicas para um planejamento que vise a recuperação econômica do estado.

Portanto, podemos concluir que a crise econômica de 2020 derivada do impacto causado pela pandemia da COVID-19 demonstrou não só as fragilidades da retomada "positiva" na geração de empregos no Rio Grande do Sul, mas também a existência de múltiplas formas de manifestação dessa no espaço. Além disso, a partir de nosso objetivo geral, constatamos que a queda na oferta de empregos formais ocasionada pela COVID-19 representa um agravamento de uma crise já existente no estado gaúcho, fruto de uma série de transformações no mundo do trabalho brasileiro dos últimos 10 anos. 


\section{Referências}

AGUIAR, S. (2020) COVID-19: a doença dos espaços de fluxos. GEOgraphia, Niterói, Universidade Federal Fluminense. v. 22, n. 48, p. 51-74.

ALVES, G. (2009) Trabalho e reestruturação produtiva no Brasil neoliberal: Precarização do trabalho e redundância salarial. Revista Katál. Florianópolis, v. 12, nº. 2, p. 188-197. Universidade Estadual Paulista (UNESP), Marília. Disponível em: <http://dx.doi.org/10.1590/s1414-49802009000200008>. Acesso em: 15 set. 2020.

ANTUNES, R. FILGUEIRAS, V. (2020) Plataformas digitais, Uberização do trabalho e regulação no Capitalismo contemporâneo. Contracampo, Niterói, v. 39, n. 1, p. 27-43.

BENETTI, M. D. Globalização e desnacionalização do agronegócio no Brasil e no Rio Grande do Sul. Porto Alegre: FEE, 2004.

BRASIL. (2020) Ministério da Saúde. Boletim Epidemiológico, n. 1, janeiro, 2020. Disponível em: <https://portalarquivos2.saude.gov.br>. Acesso em: 25 Ago. 2020.

BRASIL. (2017) Lei no 13.467, de 13 de julho de 2017. Altera a consolidação das Leis do Trabalho (CLT), aprovada pelo Decreto-Lei ${ }^{\circ} 5.452$, de $1^{\circ}$ de maio de 1943, e as Leis nos 6.019, de 3 de janeiro de 1974, 8.036, de 11 de maio de 1990, e 8.212, de 24 de julho de 1991, a fim de adequar a legislação às novas relações de trabalho. Brasília: Casa Civil. Disponível em: <http://www.planalto.gov.br/ccivil_03/_ato2015-2018/2017/lei/L13429.htm>. Acesso em: 22 dez. 2020.

CASTRO, Antonio B.; SOUZA, Francisco E. Pires. A Economia Brasileira em Marcha Forçada. Rio de Janeiro: Paz e Terra, 1985.

CADASTRO GERAL DE EMPREGADOS E DESEMPREGADOS/CAGED. Estatísticas mensais do Emprego Formal. Portal Eletrônico do Novo CAGED. Disponível em: <http://pdet.mte.gov.br/novocaged> Acesso em: 26 Set. 2020.

CATÃO, Rafael de Castro. (2016) Expansão e consolidação do complexo patogênico do dengue no estado de São Paulo: difusão espacial e barreiras geográficas. Tese (Doutorado em Geografia) Faculdade de Ciências e Tecnologia, Universidade Estadual Paulista, campus de Presidente Prudente. CENTRO EUROPEU DE PREVENÇÃO E CONTROLE DE DOENÇAS/CEPCD. (2020) Doença de COVID19. Portal Eletrônico do CEPCD. Disponível em: <https://www.ecdc.europa.eu/en/2019-ncovbackground-disease>. Acesso em: 23 Ago. 2020.

COMIM, F. BAGOLIN, I. (2002) Aspectos qualitativos da pobreza no Rio Grande do Sul. Ensaios FEE, Porto Alegre, v. 23, Número Especial.

COSTA, A, L. (2020) Precarização do trabalho e reorganização da mão de obra no contexto de pandemia. Revista Novos Rumos Sociológicos. v. 8, n. 14, p. 90-115.

CRUZ, Paulo D. Notas sobre o endividamento externo brasileiro nos anos setenta. In: L. G. Belluzzo; Coutinho, R. (orgs.). Desenvolvimento Capitalista no Brasil, vol. 2. São Paulo: Brasiliense, 1983.

DRUCK, G. DUTRA, R. SILVA, S, C. (2019) A contrarreforma neoliberal e a terceirização: a precarização como regra. Cad. $\mathrm{CRH}$ [online], v. 32, n. 86, p. 289-306.

DUARTE, T. S. et al. (2020) COVID-19 e a distribuição territorial desigual do sistema técnico hospitalar: uma análise da região de saúde sul do Rio Grande do Sul. Revista Ensaios de Geografia. Niterói, vol. 5, no 10, p. $109-115$.

FARIA, R. et al. (2020) Difusão da COVID-19 nas grandes estruturas territoriais do estado do Rio Grande do Sul, Brasil. Hygeia :Revista Brasileira de Geografia Médica e da Saúde, [S.L.], edição especial, p. 426-435. 
FERREIRA JUNIOR, R. R; SANTA RITA, L. P. (2020) Impactos conjunturais da pandemia da COVID-19 na Economia: limites, desafios e políticas. In: SENHORAS, E. M. (org.). Impactos Econômicos da Pandemia da COVID-19. 1.ed. Boa Vista: EdUFRR.

FOLHA DE SÃO PAULO. (2017) Reforma trabalhista. Disponível em: <https://www1.folha.uol.com.br/mercado/2017/04/1872602-terceirizacao-e-reforma trabalhistavao-gerar-empregos-diz-meirelles.shtml >Acesso em: 14 out. 2020.

FURTADO, C. Formação Econômica do Brasil. 32. ed. São Paulo, SP: Companhia Editora Nacional, 2003.

FURTADO, C. O mito do desenvolvimento econômico. São Paulo: Círculo do Livro, 1974

FURTADO, C. Subdesenvolvimento e Estagnação na América Latina. Rio de Janeiro: Civilização Brasileira, 1966.

GIAMBIAGI, F., VILLELA, A., CASTRO, L.B., HERMAN, J.(org.). Economia Brasileira Contemporanea:1945-2010. 2a ed. Rio de Janeiro: Editora Elsevier, 2011.

GENNARI, A. M. Globalização, neoliberalismo e abertura econômica no Brasil nos anos 90. Revista PESQUISA \& DEBATE, Volume 13, n. 1(21), p. 30-45, 2001.

HARVEY, D. (2011). The Enigma of Capital and the Crisis this Time. New York: New York University Press.

HEIDRICH, Á. (2000) Além do latifúndio: geografia do interesse econômico gaúcho. Porto Alegre: Editora da UFRGS.

IBGE. (2017) Produto interno Bruto dos municípios do Brasil. Disponível em: $<$ https://www.ibge.gov.br/estatisticas/economicas/contas-nacionais/9088-produto interno-brutodos-municipios.html >Acesso em: 12 Fev. 2020.

IBGE. (2020) Pesquisa Nacional por Amostra de Domicílios Contínua - PNADC. Divulgação Mensal. Disponível em: <https://www.ibge.gov.br/estatisticas/sociais/ populacao/9171-pesquisa-nacionalpor-amostra-de-domicilios-continua-mensal. html?=\&t=resultados>. Acesso em: 08 Fev. 2020.

MATTEI, L. HEINEN, V, L. (2020) Impactos da crise da COVID-19 no mercado de trabalho brasileiro. Revista de Economia Política, v. 40, nº 4, p. 647-668.

PRADO JR., C. Formação do Brasil Contemporâneo. 23. ed. São Paulo: Brasiliense, 2008.

ORGANIZAÇÃO PARA A COOPERAÇÃO E O DESENVOLVIMENTO ECONÔMICO/OCDE. (2020) Global economy faces gravest threat since the as coronavirus spreads. OECD Website. Disponível em: <http://www.oecd.org>. Acesso em: 29 Ago. 2020.

ORGANIZAÇÃO MUNDIAL DO COMÉRCIO/OMC. (2020) Agency chiefs issue joint call to keep food trade flowing in response to COVID-19. Organização Mundial de Comércio. Disponível em: <https://www.wto.org/english/news_e/news20_e/igo_26mar20_e.htm> Acesso em: 26 dez. 2020.

RIO GRANDE DO SUL. (Estado). (2020) Modelo de Distanciamento Controlado Rio Grande do Sul. Distanciamento Controlado. Disponível em: <https://distanciamentocontrolado.rs.gov.br> Acesso em: 26 Set. 2020

RIO GRANDE DO SUL. (Estado). (2012) Secretaria do Planejamento, Mobilidade e Desenvolvimento Regional. Perfil Socioeconoímico: COREDE Campos de Cima da Serra. Disponível em: <https://planejamento.rs.gov.br/upload/arquivos/201512/15134128-20151117100501perfisregionais-2015-campos-de-cima-da-serra.pdf >. Acesso em: 10 jan. 2021.

ROUBINI, N. (2020) A Greater Depression? Project Syndicate, p. 1-5. Disponível em: $<$ https://www.project-syndicate.org/commentary/coronavirus-greater-great-depression-bynourielroubini-2020-03>. Acesso em: 24 dez. 2020.

SANTOS, M. (1996) A natureza do espaço: Técnica e tempo. Razão e emoção. 4. ed. São Paulo: Hucitec. 392 p.

SANTOS, M. (2003) Por uma outra globalização: do pensamento único à consciência universal. 10. ed. Rio de Janeiro: Record. 174 p.

SANTOS, M. SILVEIRA, M. L. (2001) O Brasil: território e sociedade no início do século XXI. Rio de Janeiro: Record

SOARES, P R. R.; SCHNEIDER, L. P. (2012) Notas sobre a desconcentração metropolitana no Rio Grande do Sul. Boletim Gaúcho de Geografia, v. 39, p. 113-28. 
SPOSITO, M. E. B.; GUIMARÃES, R. B. (2020) Por que a circulação de pessoas tem peso na difusão da pandemia. Difusão da Covid-19 no país segue modelo relacionado a interações espaciais na rede urbana. UNESP. Universidade Estadual Paulista Júlio de Mesquita Filho. Disponível em: <https://www2.unesp.br/portal\#!/noticia/35626/por-que-a-circulacao-de-pessoas-tem-peso-nadifusaoda-pandemia>. Acesso em: 10 Jan. 2021.

ZANATTA, M. J; HALBERSTADT, A. I; CERUTTI, J. M. (2020) Modelo de distanciamento controlado: Atuação do governo do estado do Rio Grande do Sul Frente à pandemia da COVID-19. Boletim de conjuntura (boca). Ano. II, v. 3, nº. 7, Boa Vista. 